\title{
Cardiac tamponade after pulmonary valvuloplasty for presumed pulmonary valvular stenosis in a patient with double-chambered right ventricle: An unexpected diagnosis during emergency surgery
}

\author{
Gökhan İlhan, Şahin Bozok, Şaban Ergene, Sedat Ozan Karakişi, Hakan Karamustafa, Nebiye Tüfekçi
}

Received: July 03, 2014 Accepted: December 27, 2014 Published online: February 10, 2015

\begin{abstract}
Double-chambered right ventricle (DCRV) is a rare cardiac congenital anomaly characterized by an obstruction of subinfundibular region by abnormal muscle bands. Herein, we report a case with DCRV and cardiac tamponade requiring urgent surgery following pulmonary valvuloplasty due to presumed pulmonary valvular stenosis. A 42-year-old female patient was admitted to cardiology department with a complaint of dyspnea. The patient was diagnosed with pulmonary valvular stenosis by echocardiography and cardiac catheterization. A maximum hemodynamic gradient of $110 \mathrm{mmHg}$ was detected in the right ventricular outflow tract (RVOT). The patient required emergency surgery due to the right atrial laceration and cardiac tamponade following an attempt for pulmonary valvuloplasty. Right atrial injury was repaired by primary suturing and a longitudinal incision was made to the RVOT. A fibrotic, circular muscular ring in the subinfundibular region was resected. Pressure tracings from the right ventricle and pulmonary arteries revealed resolution of pressure gradient. Preoperative correct diagnosis of DCRV and associated pathologies increase the success of surgical procedures and may prevent unexpected complications for both the surgeon and the patient.
\end{abstract}

Keywords: Cardiac tamponade; double-chambered right ventricle; pulmonary valvuloplasty.

Double-chambered right ventricle (DCRV) is a rare congenital anomaly causing the right ventricular outflow obstruction with a prevalence of $1-1.5 \%$ among all congenital cardiac anomalies. ${ }^{[1,2]}$ It is characterized by abnormal muscular bands in the subinfundibular region which obstructs the outflow and separates the right ventricle into two cavities, namely inflow and outflow chambers. The abnormal muscular tissue produces a pressure gradient between these chambers. The majority of patients are diagnosed in childhood and early adulthood with a preponderance below the age $20 .^{[2,3]}$

Although the natural history is still not clarified, DCRV frequently accompanies ventricular septal defect (VSD), causing the long-standing right ventricular outflow obstruction. ${ }^{[1]}$ Although other cardiac malformations often coexist with DCRV, an isolated DCRV is an extremely rare pathology. Approximately $80 \%$ of the patients have membranous VSD. Aneurysmatic pouching of the membranous septum, known as membranous septum aneurysm (MSA), may also develop. Hypertrophic muscular bands within the right ventricle impede flow, producing a pressure gradient. Thus, differential diagnosis includes other causes of the right ventricular outflow tract (RVOT) obstruction.
If DCRV is not ruled out in a patient with RVOT obstruction, the area between two chambers surrounded by muscular bands may be mistakenly identified as VSD during surgery and closure of this area may prove fatal.

Herein, we report an adult case with DCRV and RVOT obstruction, who underwent pulmonary valvuloplasty due to presumed pulmonary valvular stenosis and required emergency surgery due to cardiac tamponade.

\section{CASE REPORT}

A 42-year-old female patient was admitted to cardiology department with the complaints of dyspnea, fatigue and chest pain. Physical examination revealed a $4 / 6$ systolic murmur in the mesocardiac area. Electrocardiography demonstrated the right ventricular hypertrophy voltage criteria. The patient was diagnosed with pulmonary valvular stenosis by

Department of Cardiovascular Surgery, Medical Faculty of Recep Tayyip Erdoğan University, Rize, Turkey

Corresponding author: Şahin Bozok, M.D. Recep Tayyip Erdoğan Üniversitesi Tip Fakültesi Kalp ve Damar Cerrahisi Anabilim Dal, 53200 Rize, Turkey.

Tel: +90 464 - 2170365 e-mail: sahinboz@yahoo.com 
echocardiography and cardiac catheterization which showed a maximum pulmonary artery pressure of $15 \mathrm{mmHg}$, right ventricular pressure of $125 \mathrm{mmHg}$ and a gradient of $110 \mathrm{mmHg}$ between these chambers (Figures 1a, b). The patient underwent pulmonary valvuloplasty and cardiac tamponade ensued due to the right atrial injury requiring emergency surgery.

\section{Surgical procedure}

Since the patient was hypotensive due to cardiac tamponade, urgent median sternotomy was performed under general anesthesia. A large hematoma was observed around the heart within the pericardial cavity. After debridement of hematoma, the source of bleeding in the right atrial free wall was repaired primarily using 4/0 prolene sutures. After aortic and bicaval cannulation, cardiopulmonary bypass was initiated under moderate hypothermia $\left(28^{\circ} \mathrm{C}\right)$. As we obtained no information related to DCRV and due to emergent nature of the procedure, we did not measure the right atrial, right ventricle inlet, and pulmonary artery pressures. Following cross-clamping, diastolic arrest was achieved by cardioplegia. Right atriotomy and a longitudinal incision of RVOT were performed. No evidence of stenosis in the pulmonary valve was observed. However, an abnormal muscular tissue which divided the right ventricle into two chambers was noticed. The right ventricle was inspected using right atriotomy and right ventriculotomy (Figure 2a).
With the diagnosis of double-chambered right ventricle, abnormal hypertrophic and fibrotic bands which aligned circularly were resected. Septum, moderator band, papillary muscle of the tricuspid valve were spared during resection. No additional abnormalities including VSD were present. Right atrium was closed primarily, whereas right ventriculotomy was repaired with a pericardial patch (Figure 2b). Cardiopulmonary bypass was ceased. Pressure readings from the right ventricle dropped to $30 \mathrm{mmHg}$ in the proximal right ventricle from $125 \mathrm{mmHg}$ and the gradient dropped to $12 \mathrm{mmHg}$ from $110 \mathrm{mmHg}$. Systemic arterial pressure was $110 / 70 \mathrm{mmHg}$ at the end of the procedure.

The patient remained stable in the postoperative period without any complications and was discharged at the $10^{\text {th }}$ postoperative day.

\section{DISCUSSION}

Lesions causing the right ventricular outflow obstruction may be at valvular, supravalvular or infundibular level. Infundibular obstructions are further classified as high, medium and low. Moreover, abnormal muscular bands of the right ventricle, membranous septum aneurysm, accessory tricuspid leaflet, Ebstein's anomaly type $\mathrm{C}$ and $\mathrm{D}$, hydatid cyst of the infundibular septum, and neoplasms may cause RVOT obstruction.
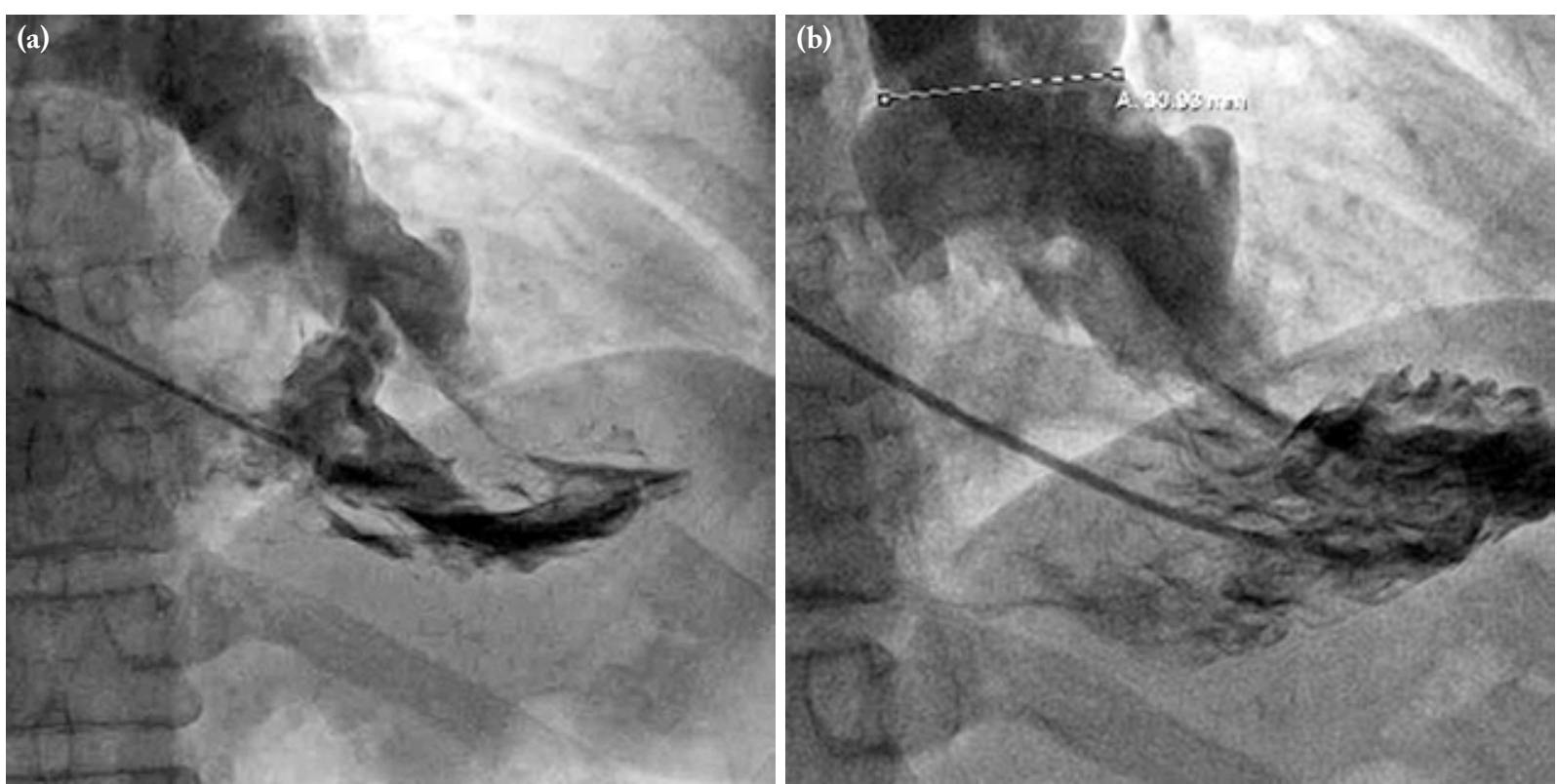

Figure 1. (a) Right anterior oblique right ventriculography showing a muscular band dividing the right ventricle into two cavities and (b) typical double cavity view. 

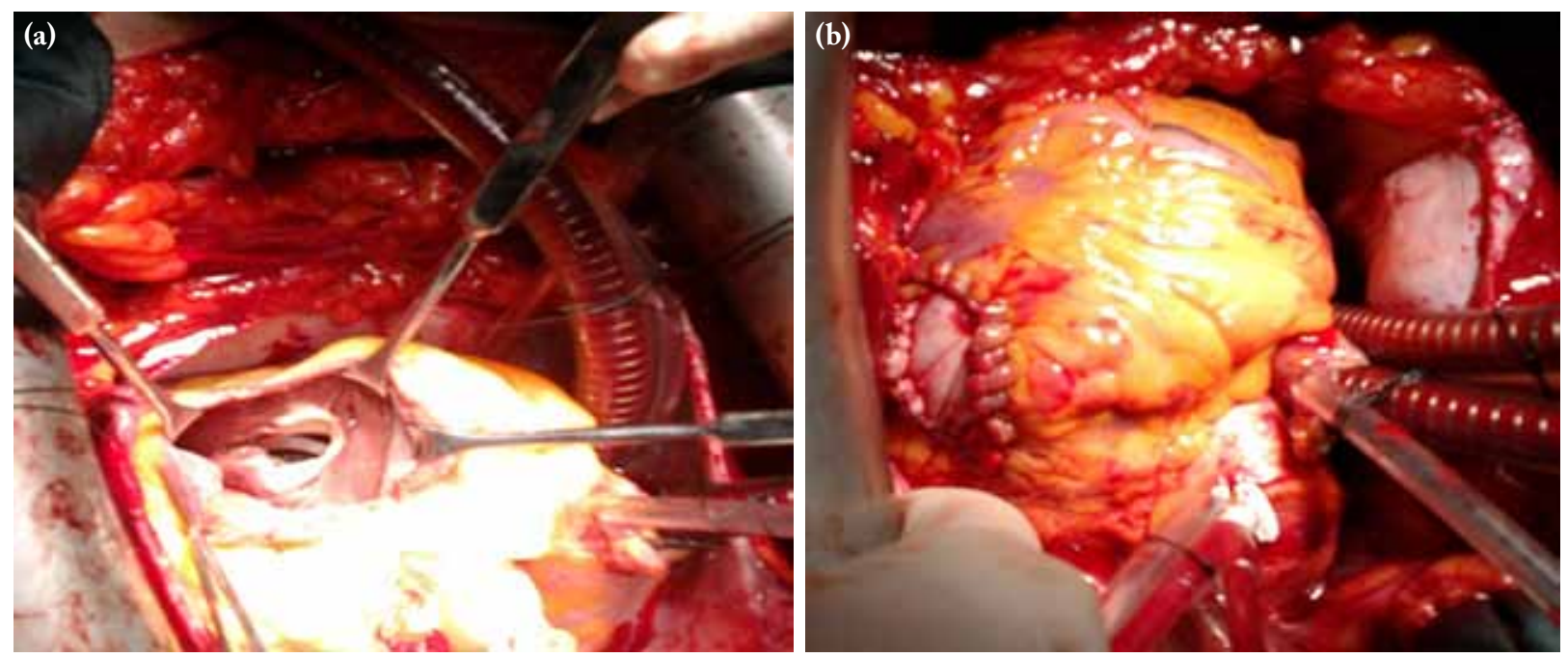

Figure 2. After right ventricular incision, (a) muscular band dividing the right ventricle into two cavities is seen. (b) Right ventriculotomy repaired with a pericardial patch.

Formerly, DCRV, a rare cause of RVOT obstruction, was first described by Lucas et al. ${ }^{[4]}$ as a pathology resulting from abnormal muscular bands in the subinfundibular region. Moreover, they reported that two patients were deceased after closure of the defect with the suspicion of VSD.

This pathology includes two chambers: proximal chamber has high pressure, whereas distal chamber is below normal or normal. Pulmonary valve and infundibulum are usually normal. Also, DCRV should be differentiated from other forms of RVOT obstructions: infundibular fibromuscular stenosis, reactive crystal hypertrophy and tetralogy of Fallot (TOF) may also cause subpulmonary pressure gradient. These pathologies can be differentiated by decreased trabeculations of the right ventricle. In addition, Goor and Lillehei ${ }^{[5]}$ reported the following points in differentiating DCRV and TOF: In TOF aorta is dextropositioned and VSD is always below obstruction. High septoparietal muscular bands, unlike abnormal muscular bands, are in the infundibulum and these bands do not cross the right ventricular cavity. ${ }^{[4]}$ Moreover, the conus is usually higher. In patients with DCRV and VSD, aorta is normally placed, VSD may not be below the level of obstruction, and it may also be supracristal. Additionally, VSD in DCRV is accompanied with abnormal muscular bands, and these bands cross the right ventricular cavity. The conus septum is normally placed..$^{[5]}$

Furthermore, DCRV is usually accompanied with several anomalies, the most common of which is
VSD. ${ }^{[1]}$ However, an isolated DCRV is an extremely rare pathology. In a series of 24 patients, Fellows et al. ${ }^{[6]}$ demonstrated $85 \%$ VSD and $8 \%$ membranous septum aneurysm (MSA). In addition to VSD (80-95\%), pulmonary valve stenosis (33\%), discrete subaortic stenosis, coronary artery anomalies (single coronary artery), double outlet right ventricle, and TOF may be also seen in patients with DCRV ${ }^{[6]}$ In a study including patients undergoing surgery for VSD, Simpson et al. ${ }^{[7]}$ found the frequency of DCRV to be $10-11 \%$.

McElhinney et al. $^{[3]}$ reported that RVOT obstruction may be progressive and symptomatic in patients with DCRV. Thus, they suggested surgical treatment in adult patients, in the event of symptoms, coexisting pathologies, and patients with severe obstruction, even if they were asymptomatic. Similarly, our patient remained asymptomatic following surgery.

The main diagnostic tool for DCRV is echocardiography. Cardiac catheterization is the gold standard to measure the proximal and distal chamber pressures and calculate the gradient. Hachiro et al. ${ }^{[1]}$ suggested four criteria for the diagnosis of DCRV: systolic pressure gradient between the right ventricle inflow and outflow tracts, subinfundibular high/low obstruction and abnormal muscular bands in the right ventriculography, lack of infundibular hypoplasia, and direct visualization of intracardiac muscle bands during surgery. Right ventriculography may not be 
diagnostic in every patient. However, during surgical exploration, DCRV is easily diagnosed. We believe that misdiagnosis of pulmonary stenosis in our case is due to an inexperience, and lack of information about DCRV, an extremely rare cause of RVOT obstruction. As a result, we could diagnose the patient correctly at surgery.

In a series of 40 patients, Hachiro et al. ${ }^{[1]}$ reported that they performed right atriotomy, combined pulmonary arteriotomy, and most commonly right ventriculotomy. During surgery, care must be given to evaluate the tricuspid papillary muscles. Similarly, we performed right atriotomy and a longitudinal incision to RVOT. These two combined incisions gave us an excellent view to excise abnormal muscular tissues.

In long standing pulmonary stenosis, infundibular hypertrophy usually develops. Therefore, even the pulmonic valvular stenosis is certain both before and after valvuloplasty procedure, gradient from multiple places should be obtained routinely. If the right ventricle, infundibular and pulmonary artery pressures are measured, it can be seen that there is no transvalvular gradient. On the other hand, this type of measurement is essential, since the procedure is sometimes successful, but the right ventricle pressure can be high due to the infundibular gradient. Furthermore, it should be emphasized that routine right ventricular angiography is advised before the valvuloplasty procedure. Angiographic appearance of the lateral view of the right ventricle may help to detect the exact location of stenosis. It may also give information not only where you put the balloon, but also function of the pulmonary valve.

In conclusion, correctly diagnosis of DCRV in the preoperative stage and excluding other causes of RVOT obstruction are of utmost importance. As DCRV may cause difficulties in the evaluation and surgery, special care on perioperative exploration and systematic direct pressure recording from each chamber may be helpful in patients with VSD and pulmonary valve stenosis. Successful detection of DCRV and associated pathologies may increase safety, the success of the surgical procedure, and prevent unexpected complications for both the patient and the surgeon.

\section{Declaration of conflicting interests}

The authors declared no conflicts of interest with respect to the authorship and/or publication of this article.

\section{Funding}

The authors received no financial support for the research and/or authorship of this article.

\section{REFERENCES}

1. Hachiro Y, Takagi N, Koyanagi T, Morikawa M, Abe T. Repair of double-chambered right ventricle: surgical results and long-term follow-up. Ann Thorac Surg 2001;72:1520-2.

2. Ozsoyler I, Bozok S, Yilik L, Kestelli M, Ilhan G, Gurbuz A. Double-chambered right ventricle: a case report. Turk Gogus Kalp Dama 2005;13:356-8.

3. McElhinney DB, Chatterjee KM, Reddy VM. Doublechambered right ventricle presenting in adulthood. Ann Thorac Surg 2000;70:124-7.

4. Lucas RV Jr, Varco RL, Lillehei CW, Adams P Jr, Anderson RC, Edwards JE. Anomalous muscle bundle of the right ventricle. Hemodynamic consequences and surgical considerations. Circulation 1962;25:443-55.

5. Goor DA, Lillehei CW. Congenital malformations of the heart. In: Goor DA, Lillehei CW, editors. Congenital Malformations of the Heart: Embryology, Anatomy, and Operative Considerations. 1st ed. New York: Grune \& Stratton; 1975. p. 1-37.

6. Fellows KE, Martin EC, Rosenthal A. Angiocardiography of obstructing muscular bands of the right ventricle. AJR Am J Roentgenol 1977;128:249-56.

7. Simpson WF Jr, Sade RM, Crawford FA, Taylor AB, Fyfe DA. Double-chambered right ventricle. Ann Thorac Surg 1987;44:7-10. 